\title{
INFORMATION TECHNOLOGY APPARATUSES
}

\begin{abstract}
The article presents an outline of various Information Technology apparatuses and the use of IT tools in the modern world. The main IT apparatuses which are described in this article are Cloud computing, venture content management, mobile technology, web based conferencing system and social media. The main goal of this article to aware the society that how beneficial the IT apparatuses can be in our day to day life, in business and in social media. Like the Mobile technology has changed our day to day life thoroughly. We can communicate with the people around the world; can know the weather forecast and so on. This section starts by quickly presenting two ideas that are bound together in the thought of computer upheld business advancement. Moreover the challenges and opportunities in Information technology world are described.
\end{abstract}

KEYWORDS: IT apparatuses, Cloud Computing, Mobile technology, Social Media

\section{INTRODUCTION}

One of the most significant assignments that endeavors face these days is the streamlining of business forms. This empowers their successful advancement just as usage of developments empowering presentation of new critical arrangements, work strategies and new benefits. This is just conceivable in undertakings of a high innovative and authoritative culture. Such open doors are made by the learning based economy that is ruled sideeffects and administrations whose worth determinedly relies upon learning 
and not material assets. In the advanced economy, a procedure can be seen that includes steady change from the material-escalated organizations dependent on economies of scale to economies dependent on learning and current advancements.The method for going after assets is evolving. The so far most significant material assets are being supplanted with non-material assets or more all with learning and technology (Attaran, 2003, 440-450). The essential factors describe the learning based economy are: cutting edge industry, information society administrations, administrations immersed with learning and instruction. Learning the executives is presently one of the most basic factors that decide the situation of an undertaking in the market. It doesn't just include skilful utilization of the accessible assets yet in addition getting the cooperative energy impact. So as to oversee learning, the administrative staff must have available to them not just proper assets of learning yet in addition an unmistakable structure of the executives helped by IT (information technology) apparatuses. The learning the board framework is in charge of giving the client with information that, in the wake of being handled, empowers them to make productive choices. The job of the apparatuses that process information and give information important to this reason for existing is played by IT frameworks. Their capacity is to help information the board in an association while the learning itself stays in the fitness of individuals. The target of the paper was to exhibit how the procedure of learning the board in present day undertakings is supported by information advancements. The distribution was financed with an award from the Ministry for Higher Education for statutory exercises.

\section{WRITING REVIEW}

The instruments supporting information the board fall into two gatherings, non-IT and IT ones. The non-IT assets include: Cross-useful venture groups, KM preparing and instruction, Storytelling, and Mentoring. Also, most of the IT devices supporting learning the board have a place with one of the accompanying classifications

- groupware frameworks and KM 2.0;

- the intranet and extranet;

- information warehousing, information mining, and OLAP; 
- choice emotionally supportive networks;

- content administration frameworks;

- record the executives frameworks;

- man-made brainpower apparatuses;

- recreation apparatuses;

- semantic systems.

For the most part, it tends to be expressed that they have a place with the three essential gatherings: on the web apparatuses, IT frameworks (computer applications), information assets together with pertinent programming overseeing access to them (Attaran, 2003, 440-450) .The all inclusive access to the web has implied that an ever increasing number of clients take favorable position of the worldwide system. The utilization of the web is ending up progressively serious, which shows itself in the way that web clients spend a great deal of time on the web and utilize assorted online applications. The idea of Web 2.0 alludes to the an ever increasing number of famous devices that empower two-way online correspondence. These instruments, alluded to as social, are online journals, wikis, web fora, remarking, common work territories, social entryways and various sorts of moment delivery people. The colossal notoriety of the person to person communication locales (for the most part Facebook) implies that separated from the individuals from the network, these assets are additionally utilized by organizations and establishments. These are instruments for speaking with the client as well as likewise a colossal database that can be used for example for showcasing purposes and other. The classification beginning from the 'Internet 2.0' is moved onto different thoughts identified with the utilization of the on the web social assets. A model can be learning the board - KM 2.0. The Web 2.0 devices 'encourage the improvement of the social capital by sharing information, which thus builds the potential for making the scholarly capital.' He characterizes social capital as the aggregate assets existing in the informal organizations. Incorporated administration supporting IT frameworks incorporate an entire scope of programming expected for organizations and associations. This product incorporates complex helper frameworks that are by and large even irreplaceable for the 
working of current endeavors. The information utilized in the apparatuses supporting learning the executives are accumulated in databases and information stockrooms. Furthermore, current business programming empowers procurement of information from outside, from the web arrange, counting web-based social networking. Information assembled in databases and distribution centers have a positive structure, which encourages the capacity, recovery and preparing thereof. The enormous amount of information assembled in the present-day frameworks causes a few challenges and yet, it gives exceptionally broad expository choices. Present day choice emotionally supportive networks can quickly compute pointers that chiefs need so as to deal with the undertaking. Such a capacity is satisfied by Business Intelligence (BI) frameworks (Attaran, 2003, 440-450). The OLAP solid shapes utilized in them empower achievement of three capacities: questioning and revealing (characterizing inquiries without utilizing a database programming language), multidimensional investigation (the ability of leading investigations from various points of view) and factual examination (decreasing the measure of information sent for investigations). Clearly Industry 4.0 would not be conceivable without its utilization instruments supporting learning the board. Industry 4.0 is comprised of: IoT - Web of Things and CPS (digital physical frameworks), support for an extraordinary number of information and propelled investigations (for example Enormous Data) just as a proper correspondence foundation. This mix of technology, industry and digitalisation has made another quality alluded to as the fourth mechanical transformation.

\section{Techniques}

So as to imagine the supporting of the procedure of learning the board by information innovations, chose markers describing the usage of ICT (information and correspondence advances) in different sorts of undertakings the nation over were aggregated. It was accepted that it isn't only its accessibility instruments at the offices worried that issues yet in addition the degree to which these instruments are used. The paper utilizes information distributed by Computerworld (2016), Gartner Gathering, 
Eurostat, and World Bank. The ICT usage rates being dissected were arranged for Polish undertakings isolated by the sort of action and their size (little, medium, enormous). The household rates were looked at with the qualities pervasive in the EU.

\section{RESULTS}

It ought to be referenced that the investigation of information the board in endeavors can't be performed in disconnection from an examination of the general public inside which the endeavor works. That what kind of learning assets are accessible to an endeavor relies upon the representatives' training and experience. That how mechanically progressed are the items or administrations that can be promoted depends on the clients' acquiring power as well as on their level of information. By method for instance, IT organizations won't probably sell programming in the event that clients need more computers and cell phones. Likewise the way of contacting the group of spectators can rely upon the degree of clients' information, and thus, on the instruments utilized for picking up information. It doesn't make any sense to begin an online shop if the imminent clients don't utilize the web. The utilization of the web is one of the pointers that permits assurance of the method for gaining information by individuals looking for it. Outline 1 presents the quantity of web clients per 100 individuals. Clean clients were contrasted and clients around the world, in the European Union and in the Baltic nations (Cartelli, 2009, 795-797). The elements of changes with respect to the utilization of the worldwide system demonstrates that our nation, in spite of being over the worldwide normal, altogether goes astray from the normal incentive for the part conditions of the European Union. This circumstance has not changed since the 1990s.

\section{EXAMPLES OF INFORMATION TECHNOLOGY APPARATUSES}

In case you're associated with the universe of business, you realize that it is so imperative to stay up with the latest on new tech apparatuses that could make your organization run smoother, all the more proficiently, and all the more productively. Advances in computer equipment and programming have 
improved business capacities in manners that couldn't have been envisioned 25 years back-and will keep on improving investigating the not really far off future. Here are only five of these ongoing information technology apparatuses that you should consolidate into your organization to help improve the life of your business.

Here are some examples of Information technology apparatuses:

1. Cloud Computing

2. Venture Content Management

3. Mobile Technology

4. Web based Conferencing Systems

5. Social Media

\section{Cloud Computing}

Computing itself, to be considered completely virtualized, must enable computers to be worked from circulated parts, for example, handling, stockpiling, information, and programming assets. Innovations, for example, bunch, network, and now, cloud computing, have all planned for enabling access to a lot of computing power in a completely virtualized way, by collecting assets and offering a solitary framework see. Utility computing depicts a plan of action for on-request conveyance of computing power; buyers pay suppliers dependent on utilization, like the manner by which we at present acquire administrations from conventional open utility administrations, for example, water, power, gas, and communication. Cloud computing has been begat as an umbrella term to depict a class of refined on-request computing administrations at first offered by business suppliers, for example, Amazon, Google, and Microsoft (Sarna, 2011, 4-33). It means a model on which a computing framework is seen as a "cloud," from which organizations and people get to applications from anyplace on the planet on request. 
Image 1

\section{Cloud Computing}

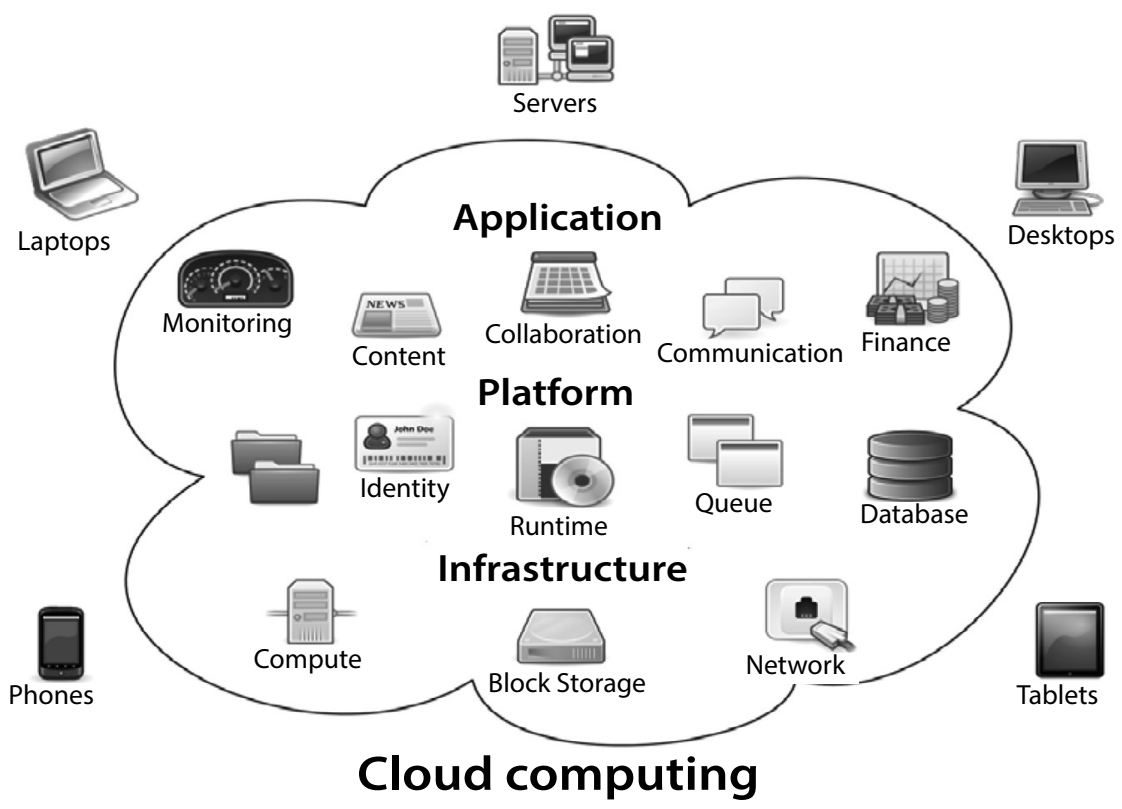

Source: https://pl.wikipedia.org

The primary guideline behind this model is offering computing, stockpiling, furthermore, programming "as an administration." Numerous experts in the business and scholarly circles have endeavored to characterize precisely what "cloud computing" is and what novel attributes it presents (Sarna, 2011, 35-40)."Cloud is a parallel and circulated computing framework comprising of an accumulation of between associated what's more,virtualised computers that are progressively provisioned and displayed as one or on the other hand increasingly bound together computing assets dependent on administration level understandings built up through exchange between the specialist co-op and customers. 
Image 2

Combination of different advances prompting the coming of cloud computing

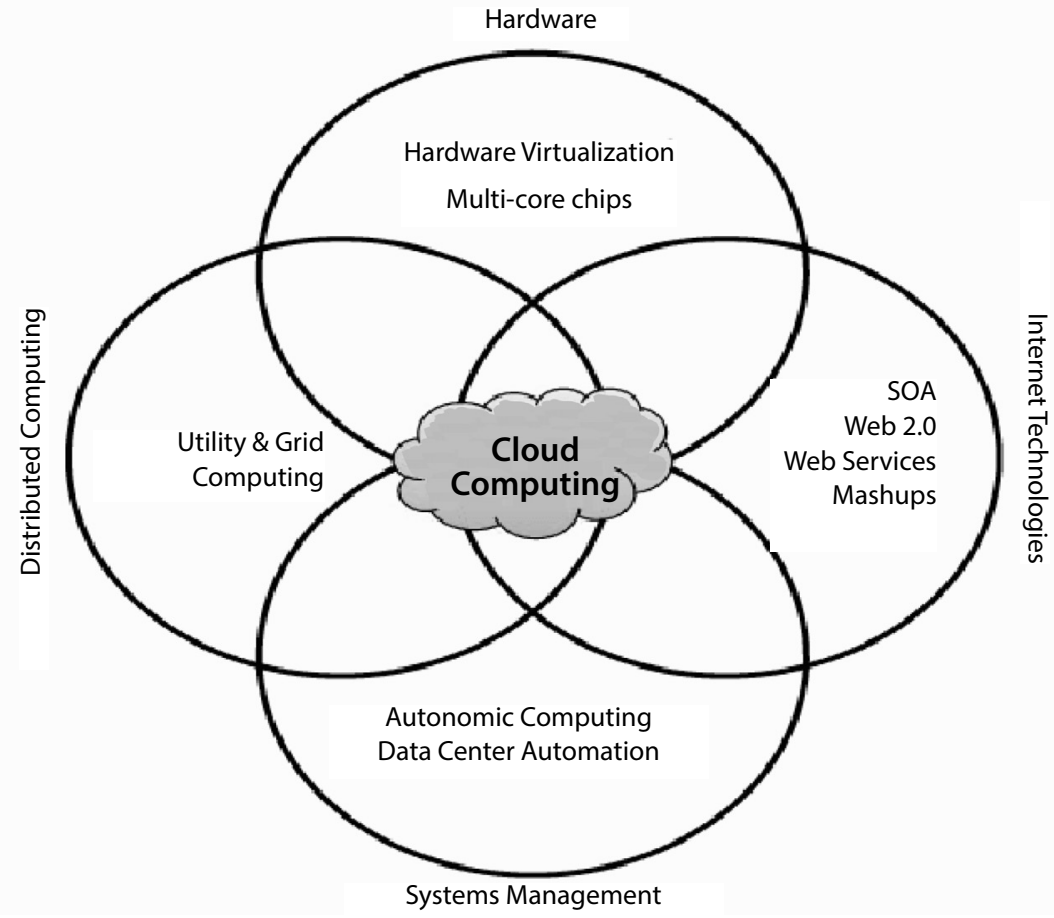

Source: https://pl.wikipedia.or€

\section{Grid Computing}

Framework computing empowers collection of circulated assets and straightforwardly access to them. Most creation lattices, for example, Tera Grid and EGEE try to offer figure and capacity assets disseminated crosswise over various authoritative spaces, with their primary center being accelerating a wide scope of logical applications, for example, atmosphere demonstrating, tranquilize structure, and protein examination. Globus Toolkit is a middleware that actualizes a few standard Grid administrations and throughout the years has supported the organization of a few administration arranged Lattice foundations and applications (Hausman, 2011, 143-159). An environment of instruments is accessible to interface with administration frameworks, 
including matrix representatives, which encourage client association with numerous middleware and actualize arrangements to meet QoS needs. Virtualization technology has been distinguished as the ideal fit to issues that have caused disappointment when utilizing matrices, for example, facilitating numerous divergent programming applications on a solitary physical stage. Toward this path, a few research ventures.

\section{Utility Computing}

In utility computing conditions, clients relegate an "utility" worth to their occupations, where utility is a fixed or time-changing valuation that catches different imperatives (due date, significance, fulfillment). The valuation is the sum they are eager to pay a specialist co-op to fulfill their requests. The administration suppliers at that point endeavor to expand their own utility, where said utility may straightforwardly correspond with their benefit. Suppliers can organize high return (i.e., benefit per unit of asset) client occupations, prompting a situation where shared frameworks are seen as a commercial center, where clients go after assets based on the apparent utility or estimation of their jobs.

\section{Hardware Virtualization}

The possibility of virtualizing a computer framework's assets, including processors, memory, and I/O gadgets, has been entrenched for quite a long time, going for improving sharing and usage of computer frameworks. Equipment virtualization permits running different working frameworks and programming stacks on a solitary physical stage.

\section{Venture Content Management}

Having the option to store and arrange your business' information appropriately is essential to the accomplishment of your organization (Hausman, 2011, 143-159). Endeavor content administration - or ECM - is a route for your business to do only that. In the event that you've been doing business for quite a while, you may have a portion of your more established documents still kept in paper organizers and put away in a container some place occupying room. With ECM, the majority of your physical 
records can be caught, overseen, put away, and safeguarded all through one simple hierarchical procedure. Procuring a gifted information technology professional can make this procedure considerably simpler for you, and can change the life of your business' put away information by making it progressively available and more straightforward to oversee.

\section{What is Enterprise Content Management (ECM)?}

It's insufficient to "oversee" content. The capacity to get to the right form of an archive or record is significant. Content must be overseen with the goal that it is utilized to accomplish business objectives. Enterprise Content Management is the precise gathering and association of data that will be utilized by an assigned group of spectators - business officials, clients, and so on. Neither a solitary technology nor an approach nor a procedure, it is a unique blend of systems, techniques, and apparatuses used to catch, oversee, store, save, and convey data supporting key authoritative procedures through its whole life cycle. Catch comes down to entering content into the framework. Oversee is your specialty alongside it, so it tends to be found and utilized by whomever it is planned for. Putting away it means thinking that it's a fitting home in your framework, be it a formal content administration framework or other data arrangement. Safeguard alludes to long haul care - filing, maybe - the act of securing it so it tends to be used anyway far into the future the association needs it to be accessible. What's more, convey is tied in with placing the data in the perfect individuals' hands right when they need it to be there. Record the executives in the long run was subsumed into content administration in no little measure on the grounds that there is more data accessible to us today than any time in recent memory, and its greater part isn't being made by us. On account of the mainstreaming of an entire scope of sources like the Web, thumb drives, cell phones, cloud, and so on., the need has quickened to manage data of assorted types: not simply regarding more media types like content versus pictures versus voice records, yet additionally as far as how organized - and in this way how promptly oversaw - everything is. Organized data is data that is profoundly characterized and not exclusively is planned to be handled by a computer program, however promptly can be - like the vast majority of the data held in social databases and followed up on by line- 
of-business arrangements. Unstructured data is, well, data that does not have a completely characterized structure, and in all likelihood will be perused and utilized by people. As models, consider the greater part of the data delivered by basic office applications (word processors, introduction programs). Semiorganized data is data that untruths some place in the middle of, similar to solicitations, buy requests, and receipts, which contain information to be computer-prepared however which come in arrangements and formats that first should be recognized and ordered - an assignment that frequently is taken care of by people yet progressively is being computerized as the devices improve. This all ends up significant when you consider the impact on your business that not dealing with these components can have! Reduced utility, loss of time, loss of profitability, conceivable rebelliousness with guidelines or corporate arrangements, the danger of genuine business interference if key stores kick the bucket or catastrophic events strike - none of them upbeat results! Adequacy, proficiency, consistence, and congruity all consolidate, in various extents, to drive the business case for content administration in many associations. Value-based content administration targets forms that attention on establishing business or achieving a choice or final product. These procedures are not centered around making content, however utilizing content to help drive activities and choices. Models incorporate receipt handling, application preparing, worker onboarding, creditor liabilities, protection claims, quiet outlines, and the preparing of grants and advances. We talk about value-based content administration here as opposed to under content administration since it more often than not requires a great deal of work process design and reconciliation with different frameworks. Being content-situated, however, it simply could have been recorded under content administration as the name proposes. For diagramming purposes, consider it consuming a space directly along the outskirt between the procedure and content controls - which are reasonably firmly integrated in any case. ECM is a progressing and advancing methodology for boosting how your content is to be utilized.

\section{Mobile Technology}

In case you're taking part in the advanced business world, odds are that correct currently you have a cell phone or tablet some place inside arms 
reach. Having mobile technology fused into your business implies that you're never again limited to the average 9-5 calendar-you can work remotely on squeezing ventures whenever and from anyplace (with a steady web association). Putting resources into versatility instruments for your business will enable you to augment profitability and help your group to team up more viably (Hausman, 2011, 147-149).

\section{Web based Conferencing Systems}

With web based conferencing frameworks, taking long, costly excursions for work can be a relic of days gone by. At the point when it's unrealistic to meet with colleagues or potential clients face to face, having a well-bolstered web conferencing stage can be a brilliant substitution. It's significant that you altogether investigate your alternatives and discover one that runs well for the venture you need it for however; having a rough association can truly put a damper on a significant gathering.

\section{Social Media}

Web based life is all over. Each organization, brand, and mother andpop shop has at any rate a little nearness via web-based networking media-for bunches of valid justifications. It takes into consideration direct correspondence among you and your shoppers, it builds your general nearness in the business world, and empowers you to assume responsibility for what sort of picture you're showing to the general population. Utilizing the board frameworks like Hootsuite can even enable you to watch out for various online life accounts without a moment's delay through one basic interface, making it simple for even a web-based social networking fledgling to ascend to progress. Nowadays people are using lots of social media tools such as Facebook, Twitter, Skype etc.

\section{Conclusion}

Inside the usage of the ICT technology, World accomplishes pointers that are altogether lower than the normal for the European Union. The extensive decent variety in the pace of usage of IT advances happens in the person gatherings of undertakings. The bigger organizations accomplished 
a fundamentally higher rate of immersion with IT apparatuses than the littler offices. By method for instance, while the level of undertakings having computers are higher, for the situation of huge organizations it is even more higher. A much more noteworthy disparity concerns web get to (Hausman, 2011, 143-159). Additionally, an assorted variety between the individual regions can be taken note. Execution of present day IT and computer advances (like for example computing clouds, enormous information, web based life, web based business) permit viable learning the board in endeavors. The pointers displayed in this demonstrate the administrative staff welcome the significance of information and put resources into its improvement.

\section{References}

Attaran, M. (2003). Information technology and business-process redesign. California: Business Process Management Journal. ISSN 1463-7154.

Hollander, A. (1999). Accounting, information technology, and business solutions. New York: McGraw-Hill Higher Education. ISBN 0256217890.

Bali, R. (2009). Knowledge management primer. London: Routledge. ISBN 041599232X.

Del Giudice, M. (2016). The impact of IT-based knowledge management systems on internal venturing and innovation. West Yorkshire:Emerald Group Publishing.

Cairó, O. (2010). Application of IT tools in KMS within a social ecology. Hong Kong: Academic Conferences Limited

Hausman, K. (2011). IT Architecture for Dummies . Indiana: Wiley Publishing, Inc. ISBN 0470554231.

Cartelli, A. (2009). Encyclopedia Of Information Communication Technology. New York: Information Science Reference. ISBN 9781599048451.

Sarna, D. (2011). Implementing and Developing Cloud Computing Applications. Boca Raton: Auerbach Publications Taylor \& Francis Group. ISBN 9781138382015. 
